\title{
Discordant effects of weak prestimulation on magnitude and latency of the reflex blink
}

\author{
FRANCES K. GRAHAM and G. MALCOLM MURRAY \\ University of Wisconsin, Madison, Wisconsin 53706
}

\begin{abstract}
In three experiments, the human blink response to $50-\mathrm{msec} 105-\mathrm{dB}$ white noise was markedly reduced by prior stimulation with weak tones, either $20 \mathrm{msec}$ long or coextensive with lead intervals of 30 to $240 \mathrm{msec}$. Although the inhibitory effect was greater with a 70-dB than with a 60-dB lead tone, it was not affected by increasing the lead-tone duration beyond $20 \mathrm{msec}$. At lead intervals of 30 and $60 \mathrm{msec}$, the latency of blink onset was also reduced by prestimulation, and this effect was greater with the longer lead tones. Neither effect was an artifact of responding to the lead tone itself. The simultaneous occurrence of an inhibitory change in magnitude and a facilitatory change in latency, and the differential influence of lead stimulus duration, suggest that the magnitude and latency modifications involve different neural mechanisms with different time constants.
\end{abstract}

A substantial animal literature demonstrates that magnitude of the unconditioned startle reflex can be predictably inhibited by weak prestimulation at short lead intervals. The inhibition is not due to conditioning, since it occurs without prior pairing (Hoffman \& Wible, 1970; Ison \& Leonard, 1971); or to forward masking, since the lead stimulus is less intense than the startle stimulus; or to protective ear reflexes, since it can be elicited by stimulus intensities too weak and at lead intervals too short for the activation of these reflexes (e.g., Dallos, 1973, Chap. 7). Peripheral refractory effects also appear to be ruled out by the finding that inhibition occurs whether or not prestimulation elicits electromyographic (EMG) activity during the interval between lead and startle stimuli (Hammon, McAdam, \& Ison, 1972).

The lead stimulus inhibitory effect has also been demonstrated in human subjects (Bloch, 1972; Graham, Putnam, \& Leavitt, 1975), with the acoustic blink reflex, the most persistent component of startle (Landis \& Hunt, 1939), and with the corneal reflex (Krauter, Leonard, \& Ison, 1973). In the first work in our laboratory, discussed in Graham et al., (1975), inhibition was obtained with a lead interval of $200 \mathrm{msec}$ in a within-subject design which included four lead intervals ranging from 200 to $2,000 \mathrm{msec}$. Since there was reflex facilitation at the longer

This work was supported by The Grant Foundation, by National Science Foundation Grant BMS75-17075, and by a Research Scientist Award K5-21762 from the National Institute of Mental Health. Computing services were provided through Grant FR00249 to the Laboratory Computing facility of the Medical School, University of Wisconsin. We gratefully acknowledge the assistance of David L. Sigafus who conducted the first two experiments. Address requests for reprints to Frances K. Graham, Department of Psychology, University of Wisconsin, Madison, Wisconsin 53706. intervals, the possibility needed to be excluded that the lead stimulus influence was due to contextual effects which might be particularly important with human subjects. Bloch (1972) eliminated this possibility by demonstrating inhibition with a single, 200-msec lead interval.

The present research was undertaken initially to plot the temporal course of the inhibition and to compare the effects of a brief, 20-msec lead stimulus with stimulation that continued until startlestimulus onset. The question is of interest because there is unequivocal evidence that more intense prestimulation produces more inhibition (e.g., Hoffman \& Wible, 1970; Krauter, et al., 1973). Since acoustic energy can be integrated by the nervous system over at least $100 \mathrm{msec}$ (e.g., Licklider, 1951, p. 1020f), it might be expected that longer lasting lead stimuli would produce more inhibition than a briefer lead stimulus of equal sound pressure level. Although Graham et al. (1975) found differences between brief and long-lasting stimuli that were in the expected direction, the differences were not significant; findings in rat studies have been conflicting (Hoffman \& Wible, 1969; Ison \& Hammon, 1971, Experiment 5).

Another purpose of the present research was to determine whether the lead stimulus produced concordant changes in startle magnitude and onset latency. Latency changes were consistent with magnitude changes in the Graham et al. (1975) study, i.e., significantly shorter blink latencies were obtained at the long lead intervals yielding magnitude facilitation and insignificantly longer latencies at the 200 -msec interval yielding magnitude inhibition. However, in another study of human subjects, latency changes were not concordant with a standard measure of reflex strength-the intensity required for a threshold blink. Berg (1973) found that the intensity required to elicit a blink was increased, but 
latency of the threshold blink was reduced by lead stimuli at $10-$ or $30-\mathrm{msec}$ lead intervals. While animal studies have rarely investigated latency effects, there is some evidence suggesting that lead stimulus effects on latency and magnitude may involve different processes at short lead intervals. Several studies from Hoffman's laboratory (e.g., Hoffman \& Wible, 1970; Stitt, Hoffman, Marsh, \& Boskoff, 1974) have shown that stimuli leading by $4-5 \mathrm{msec}$ can shorten latency without producing any change in magnitude. Ison, McAdam, and Hammond (1973) also found that, while lead stimuli generally affected both measures of reflex strength concordantly, peak inhibition of latency occurred at longer lead intervals $(170 \mathrm{msec})$ than the peak inhibition of magnitude $(40 \mathrm{msec})$. The authors suggested that "the latency mechanism responds more sluggishly" (p. 1037).

To investigate these questions, three studies were carried out. They each employed lead intervals of $30,60,120$, and $240 \mathrm{msec}$, selected to cover the period likely to produce peak inhibition in the human subject. When the initial study showed facilitation of latency at $30 \mathrm{msec}$, the subsequent studies were conducted to exclude the possibility that latency facilitation was produced by sensitized responding to the lead stimulus itself.

\section{METHOD}

\section{Subjects}

Twenty-seven undergraduates served as subjects in fulfillment of course requirements. There were nine males in each of the first two experiments and five males and four females in the third experiment. Four other subjects were replaced: one for participation in an eyelíd conditioning experiment during the previous week; and three for failure to meet predetermined criteria that (a) discarded trials not exceed one-half of the trials in any condition (discussed below and in Graham et al., 1975), (b) discarded trials not exceed one-third of all trials, and (c) at least one-third of control trials elicit nonzero responses.

\footnotetext{
Apparatus

Sessions were conducted with the subject seated in an IAC Model 1203A sound-attenuated chamber, isolated from the experimenter and recording equipment. Stimuli, delivered binaurally through Sharpe HA-10 MK11 circumaural earphones, consisted of $1,000-\mathrm{Hz}$ lead tones and 50 -msec broad-band white noise startle pulses generated, respectively, by a Model $200 \mathrm{CDR}$ Hewlett-Packard oscillator and a Grason-Stadler Model $901 \mathrm{~B}$ whitenoise generator $(50-10,000 \mathrm{~Hz})$. Rise and fall times were controlled, in the case of tone, by a Wisconsin electronic switch and, in the case of noise, by an Iconix audiogate. Both were nominally less than $10 \mu \mathrm{sec}$ but, because of limitations in the transient response of the phones, only $67 \%$ of the acoustic output was instantaneous; peak intensity was reached within 2 msec. Sound intensity was regulated by a McIntosh 40 audioamplifier and HewlettPackard 350D attenuator and was calibrated by a Bruel and Kjaer Model 2203 sound-level meter via a Type 4153 artificial ear and Type $41341 / 2-i n$. $(1.25-\mathrm{cm})$ condenser microphone. Intensity of the lead stimulus was $70 \mathrm{~dB}(\mathrm{~A})$ re $20 \mu \mathrm{N} / \mathrm{m}^{2}$ per ear in Experiments 1 and 2 and $60 \mathrm{~dB}(\mathrm{~A})$ in Experiment 3. Startle pulse intensity was $105 \mathrm{~dB}(\mathrm{~A})$.

A PDP-12 computer controlled stimulus delivery and sampled eyelid position every millisecond for $250 \mathrm{msec}$ following startle
}

pulse onset. In Experiments 2 and 3, lid position was also sampled during the lead interval or, in the case of the control condition (no lead stimulus), for $250 \mathrm{msec}$ prior to startle-pulse onset. Excursion of the eyelid was detected by mechanical transfer to a Conrac 85153 potentiometer mounted on a headset. Output of the potentiometer was fed into a Type 9803 Beckman strain gauge coupler and amplified by an Offner Type $R$ dynograph and Beckman 428 postamplifier before being sent to the computer. Simultaneous ink recordings permitted monitoring of baseline changes.

Latency to blink onset and peak amplitude ( \pm 33 micron) were scored off-line by a computer program that identified responses beginning in a window $21-120 \mathrm{msec}$ after stimulus onsets and discarded trials on which the lid was partially closed or in movement at the time of stimulus presentation. Details of the scoring procedure are described in Graham et al. (1975). In analyses of blink magnitude, no-response trials were assigned a score of 0.0 and discarded trials were estimated by interpolation between adjacent trials or, in the case of the first or last trials, by the average of the two following or two preceding trials.

\section{Procedure}

Each subject received 81 trials, 9 presentations of 9-trial blocks in a 9 by 9 Latin square design. A block contained one startlepulse-only control trial and 8 trials on which a lead stimulus preceded the startle pulse. The lead stimulus lasted $20 \mathrm{msec}$ on half of the 8 trials (discrete conditions) and continued until startle-pulse onset on the other half (continuous conditions). Intervals between onsets of the lead and startle stimuli were $30,60,120$, or $240 \mathrm{msec}$. The trials were separated by a random intertrial interval of 15 to $35 \mathrm{sec}$, with a mean of $25 \mathrm{sec}$. Each subject began on a different block of the Latin square and proceeded through the remaining blocks in sequence so that presentation order was balanced across subjects. Instructions emphasized the importance of sitting quietly, staying alert, and maintaining visual fixation on a horizontal strip of cloth taped approximately $1.7 \mathrm{~m}$ in front of the subject and adjusted to a comfortable height.

\section{RESULTS}

\section{Blink Magnitude}

Lead stimulation was effective in inhibiting blink, as Figure 1 illustrates and statistical analysis confirmed. Because inhibition below zero could not occur, distributions were skewed in the inhibitory conditions and treatment means and standard deviations were proportional. Analyses were therefore carried out on the log-transformed measures $(\log x+$ $1.0)$ and included analyses of the orthogonal trends over (unequal) lead intervals and, to estimate habituation, analysis of the linear trend over trials. Error terms for trend effects were based on the variance of the individual-subject trends. For tests of all effects, significant refers to $\mathrm{p}<.05$ with degrees of freedom reduced to one and the number of subjects less the number of experiments, thus correcting for the use of repeated measures (Greenhouse \& Geisser, 1959).

The control vs. lead stimulus effect was significant over all experiments, $F=88.24$, and for each experiment separately: in order, F-ratios $=51.01,29.91$, and 18.06. Experiments 1 and 2, both with a 70-dB lead stimulus, did not differ from one another but, in line with previous reports that greater lead stimulus intensity produces greater inhibition, the $70-\mathrm{dB}$ lead 


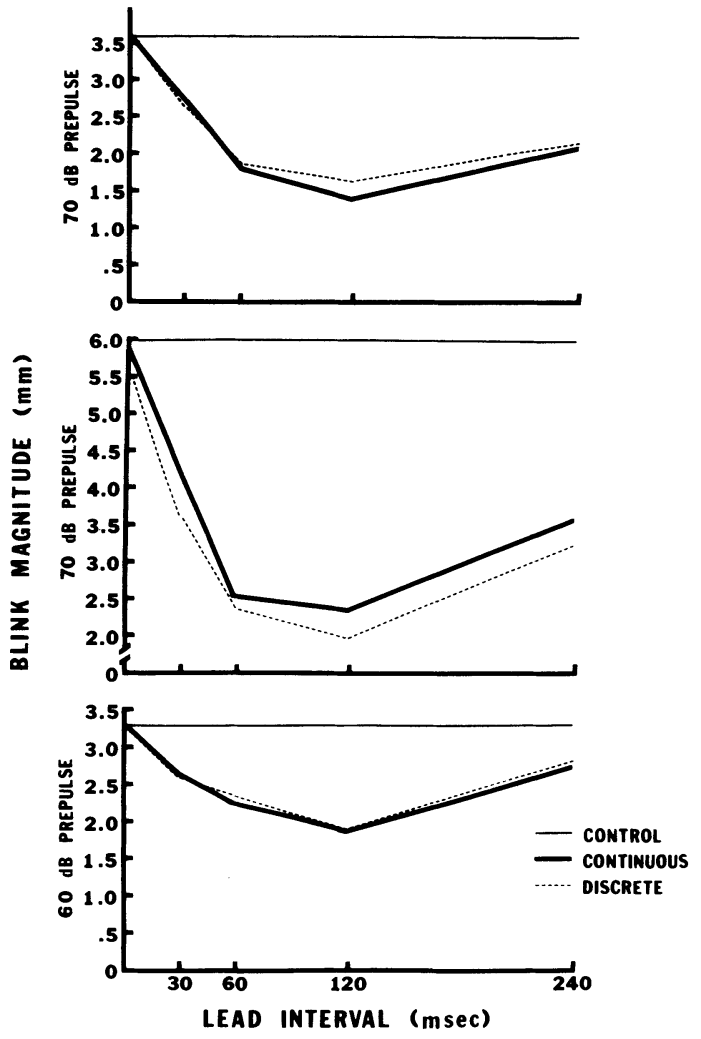

Figure 1. Blink magnitude (geometric mean) as a function of no-lead stimulation (control), 20-msec lead tones (discrete), and lead tones coextensive with lead intervals (continuous) for Experiments 1, 2, and 3, in order from top to bottom panels.

stimulus experiments did differ from Experiment 3, which employed a $60-\mathrm{dB}$ lead stimulus (Intensity by Control-Lead effect, $F=7.22$ ). Inhibition was not influenced by whether a lead stimulus was discrete or continuous. The direction of differences was inconsistent across experiments and neither alone nor in interaction with other variables did the factor account for significant variance. In contrast, length of the lead interval had a marked effect: across experiments, intervals $F=31.12$, and quadratic trend across intervals $F=93.29$; for the individual experiments, in order, intervals $F=19.12,9.56,9.90$ and quadratic intervals $F=53.36,26.01,28.40$. With the $120-\mathrm{msec}$ lead interval, which produced maximal inhibition, all subjects showed the effect. While inhibition was less at the longest and shortest intervals, it was significant at all intervals in each experiment, as evaluated by Dunnett's test (1955) using either the error term over all experiments $(\mathrm{df}=192)$ or the error term for each experiment $(\mathrm{df}=64)$.

The blink response declined over trials, as reflected in a significant trials effect $(F=5.16)$ and a linear trials effect $(F=9.54)$, but it did not decline equally in all conditions. As Figure 2 illustrates, habituation was more pronounced under control than under lead conditions (Linear Trials by Control-Lead $F=14.47$ ), and it was also more pronounced with shorter than with longer lead intervals (Linear Trials by Intervals $F=14.47$ ). Consequently, the inhibitory effect was greater on initial trials than on later trials, and the intervals yielding the most inhibition shifted from 120 and $240 \mathrm{msec}$ on early trials to 120 and $60 \mathrm{msec}$ on later trials. Habituation did not vary as a function of whether the lead stimulus was discrete or continuous or as a function of experiments, except for an uninteresting difference between Experiments 1 and 2 in habituation of the cubic trend over intervals $(F=14.06)$.

\section{Blink Latency}

The effect of lead stimulation on latency of blink onset was facilitatory, and its time course differed from the time course of the inhibitory effect; facilitation was most pronounced at the shortest intervals, and there was little evidence of any reliable effect at longer lead intervals. These findings are illustrated in Figure 3 for subjects who gave at least one nonzero blink in every condition (6 subjects each in Experiments 1 and 2, the 6 most responsive of 7 subjects in Experiment 3). Since latency was indeterminate on the many trials yielding complete inhibition, analysis of the variance associated with experiments and treatment conditions was carried out on the latencies, averaged across trials, for these 18 subjects. ${ }^{1}$ The only effects of experiments were an interaction between lead-stimulus intensity and the cubic trend over intervals $(F=9.90)$ and a differ-

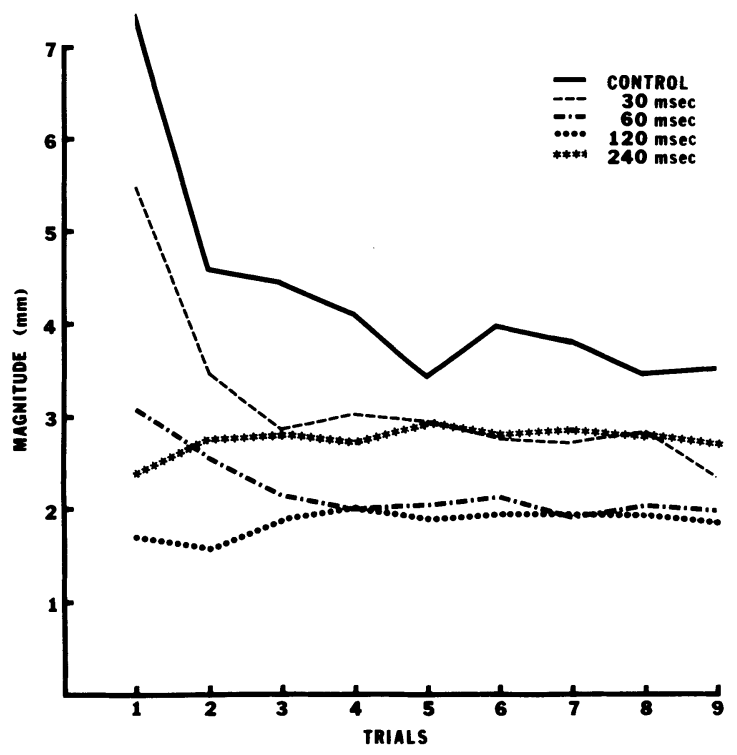

Figure 2. Blink magnitude (geometric mean) as a function of trials for no-lead stimulation (control) and for lead stimulation at lead intervals of 30,60, 120, and $240 \mathrm{msec}$. (Averaged over Experiments 1, 2, and 3 and discrete and continuous lead-stimulus conditions.) 

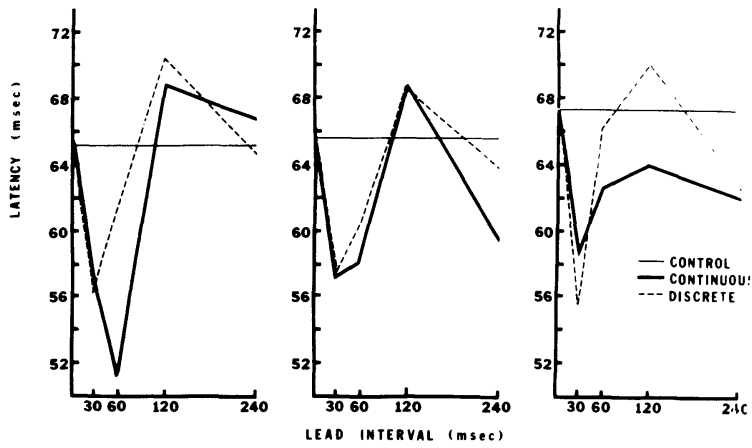

Figure 3. Latency of blink onset as a function of no-lead stimulation (control), 20-msec lead tones (discrete), and lead tones coextensive with lead intervals (continuous) for Experiments 1,2 , and 3 , in order from left to right panels.

ence between Experiments 1 and 2 in the linear trend over intervals $(F=4.83)$. However, conditions had a marked effect: lead-control difference $F=8.95$; continuous-discrete difference $F=5.01$; intervals $F=31.87$. Linear and quadratic trends over intervals were also highly significant $(\mathrm{Fs}=27.56$ and 64.46 , respectively), which implies that the relatively complex pattern of changes was characteristic of individual subjects.

Of more interest than trends across intervals are comparisons between the control condition and the latency changes at particular lead intervals. Judged by Dunnett's criteria, latency differed significantly from control latency only when lead stimuli preceded startle stimuli by 30 or $60 \mathrm{msec}$. At $30 \mathrm{msec}$, latency was facilitated both with discrete and with continuous prestimulation in each of the three experiments while, at $60 \mathrm{msec}$, discrete prestimulation did not have an effect but continuous prestimulation produced significant facilitation in both Experiments 1 and 2. Similar findings were obtained when controllead differences at each interval were evaluated (paired $t$ tests) for all subjects with nonzero blinks under a given condition. In each experiment, as well as over all experiments, significant facilitation occurred under the 30 discrete, 30 continuous, and 60 continuous conditions. Greater facilitation in the 60 continuous than in the 60 discrete condition was observed in 22 of the 26 subjects providing data and was a significant effect, $t(25)=3.90$. On the same nonzero trials, blink amplitude was significantly less than control for both 60 discrete and 60 continuous conditions [mean reduction $=2.45$ and $2.89 \mathrm{~mm}$; $\mathrm{t}(25)=4.41$ and 6.27 , respectively] and there was no difference between the conditions $[\mathrm{t}(25)=1.43]$.

Since habituation of latency could not be tested in the main analysis of variance, a special analysis compared average response latencies on the first four trials with average latencies on the last five trials for the control condition and the combined continuous and discrete $30-\mathrm{msec}$ conditions. The
24 subjects who had at least two nonzero responses in each of the four cells (Halves by Conditions) were included. Habituation, reflected in longer latencies on the last five trials, was significant $(F=9.43)$, but did not interact with the control-lead conditions $(\mathrm{F}=1.69)$.

\section{Response to Lead Stimulation}

While magnitude inhibition and latency facilitation thus appear to be reliable findings in human subjects when lead stimulation precedes startle stimulation at short intervals, the possibility of peripheral effects needs to be excluded, i.e., could inhibition be the consequence of peripheral interaction or refractoriness due to prior response to the lead stimulus and/or could short latency blinks following startle pulses be weak, long-latency blinks elicited by lead stimuli?

In theory, lead stimuli, even if ineffective in eliciting large blinks, might be capable of eliciting small lid movements. Although Berg (1973) found that the threshold for just-detectable blink, in response to $16-32 \mathrm{msec} 1,000-\mathrm{Hz}$ tones, was $85 \mathrm{~dB}$, or 15 to $25 \mathrm{~dB}$ above lead-stimulus intensities in the present research, sensitization of response to belowthreshold tones might occur since experimental conditions also included intense stimuli. Alternatively, the moderate intensity lead stimuli might be capable of evoking lid opening (McEwen, 1962; Hall \& Cusack, Note 1), presumably as part of orienting.

In practice, previous research has concluded that neither the inhibitory effect (Hammond et al., 1972) nor the latency facilitation (Berg, 1973) could be ascribed to lead-stimulus-elicited response. Hammond et al. found that rat startle, measured by a stabilimeter, was inhibited whether or not EMG activity was detected in forelimb flexor and extensor muscles during the lead interval. Berg, in her study of human blink threshold, argued that the latency-facilitated but just-detectable blinks obtained with a $30-\mathrm{msec}$ lead interval could not be due to the lead stimuli, since they were 10-25 dB less than the threshold intensity determined in the same experiment. Analyses of the present data support both of these conclusions, although, as described below, they show that some lid movement is elicited by 60 - and 70-dB stimuli and that such movement could be confounded with response due to the startle pulse.

Lid activity recorded during the 120 - and $240-\mathrm{msec}$ lead intervals of Experiments 2 and 3 was computerscored for the occurrence of both openings and closures, using the same criteria that identified responses following startle pulses. A measure of operant level, in the absence of stimulation, was similarly obtained by tabulating scorable activity in two 100 -msec windows during the 250 -msec period prior to startle pulse onset in the no-lead stimulus, control condition. Although closures followed lead 
stimuli on only a small proportion of periods, $20.0 \%$ in Experiment 2 and $14.5 \%$ in Experiment 3, these percentages significantly exceeded the operant level of $4.9 \%$ in Experiment 2 and $8.0 \%$ in Experiment $3\left(\chi^{2}=19.35\right.$ and 4.19 , respectively). Closures were not a function of lead-stimulus duration $\left(\chi^{2}=\right.$ 1.86 and 0.33$)$ or of trials $\left(\chi^{2}=3.16\right.$ and 1.98 for first four trials vs. last four trials). Scorable openings occurred in $4.9 \%$ and $3.7 \%$ of lead intervals and with no lesser frequency $(4.9 \%$ and $5.6 \%)$ during control periods.

The existence of significant responsiveness to lead stimuli could not, however, explain the inhibition of blink to startle pulses. For the 14 subjects, pooled across experiments, who had at least one blink during the 120 -msec lead interval, mean response to the startle pulse was $1.35 \mathrm{~mm}$ on trials preceded by lid movement during the lead interval compared to a mean of $2.19 \mathrm{~mm}$ on trials not preceded by movement. The difference was insignificant, $t(13)=1.31$. Further, inhibition measured by the difference from paired control trials was significant in both cases: for trials with prior movement, $\mathrm{t}(13)=4.12$; for trials without prior movement, $t(8)=3.97$ for Experiment 2 and 3.46 for Experiment 3.

To determine whether or not lead-stimulus-elicited responses could account for the latency facilitation effect, lid closures following lead stimuli in the 240-msec conditions were scored for windows of 51-150 msec and 81-180 msec. Blinks occurring in these windows would, if a startle pulse had been given 30 or $60 \mathrm{msec}$ after the lead stimulus, have fallen in the 21-120-msec window for scoring response to the startle pulse and have been indistinguishable from a short-latency response to the startle pulse. The obtained percentages of closures during lead intervals were: for Experiment 2, 22.8\% and $13.6 \%$ for the two windows, respectively; for Experiment 3, $13.6 \%$ and $8.0 \%$, respectively. The latency distributions of these responses following lead stimuli were then used to adjust distributions of responses elicited by startle pulses, i.e., in the 30 - and $60-\mathrm{msec}$ conditions, for every response elicited by a lead stimulus that fell within the range of latencies of responses presumably elicited by a startle pulse, a startlepulse response approximately coincident in latency $( \pm 5 \mathrm{msec})$ was discarded. Latency facilitation was still significant when control-lead differences in the reduced data were evaluated by paired $t$ tests: Experiment 2 , for 30 discrete, 30 continuous, and 60 continuous conditions, $\mathrm{t}(8)=5.11,7.41$, and 2.07; Experiment $3, t(8)=5.69,4.26$, and 3.12 , respectively.

\section{DISCUSSION}

The present findings demonstrate, once again, the robustness of the startle-inhibiting effect of a lead stimulus at short intervals, and they show, further, that the temporal course in humans is similar to that found with rats and pigeons (e.g., Stitt, 1975; Stitt et al., 1974). The findings also demonstrate that facilitation of blink latency occurs at lead intervals yielding significant inhibition of blink magnitude. The discordant change in these usually concordant measures of reflex strength suggests that latency and magnitude effects may involve different processes. The processes not only have a different time course, magnitude inhibition peaking at $120 \mathrm{msec}$ and latency facilitation at 30 or $60 \mathrm{msec}$, but they appear to be differentially dependent on the integration of energy over time. While magnitude inhibition was maximal with lead stimulus durations of $20 \mathrm{msec}$, latency facilitation was more persistent when lead stimuli continued for the full 30 - or 60-msec lead interval.

These data set certain constraints on the mechanisms that could account for them. The absence of any increase in inhibition with increase in stimulus duration beyond $20 \mathrm{msec}$, taken in conjunction with the finding of greater inhibition with greater leadstimulus intensity, implies that it is the magnitude of the change in intensity and not total stimulus energy that produces the inhibitory effect. This conclusion agrees with the conclusion drawn from rat studies which showed that changes in tone frequency or in the offset of a long-lasting tone could also inhibit response to a subsequent startle stimulus (Stitt et al., 1974). In brief, the inhibitory effect of lead stimulation appears to be due solely to its transient and not to its steady-state characteristics.

In contrast, not only did latency facilitation last longer when stimulus duration was greater than $20 \mathrm{msec}$ but, with continuous stimulus durations and lead intervals longer than those explored in the present experiments, facilitation of both magnitude and latency is a direct function of stimulus duration (Bloch, 1972; Graham et al., 1975). The facilitating effect of continuous lead stimulation with durations longer than about $400-1,000 \mathrm{msec}$ is well established in animal studies (e.g., Hoffman \& Wible, 1969; Stitt et al., 1974), where it is seen even after several hours of continuous stimulation (Hoffman, Marsh, \& Stein, 1969); in human studies, the effect occurs at least up to $2,000 \mathrm{msec}$ (Graham, 1975) but was not obtained with stimulation lasting for $20 \mathrm{sec}$ (Putnam, 1975). In previous work, the early, brief period of latency facilitation, seen in rats with lead stimuli of 4 to 5 msec (e.g., Stitt et al., 1974), has not been viewed as part of the same process that produces facilitation of amplitude and latency at long intervals. The present finding that both effects are sensitive to the temporally integrated intensity of prestimulation suggests that they may reflect a single process, discontinuous because it is overridden for a short period by the inhibitory effect. However, it is still necessary to account for differential effects of 
facilitatory and inhibitory processes on latency and magnitude.

Since the early period of latency facilitation overlaps in time the inhibition of magnitude, the two processes must act, at some point, on different loci or through different systems. If only a single system were involved, effects on synaptic efficiency mighi be either facilitatory or inhibitory, but the same factor that increased or reduced firing efficiency, and thus output magnitude, would be expected to affect output latency concordantly. The fact that the facilitatory and inhibitory effects are associated with steady-state and transient properties of stimulation, respectively, suggests that neurons differentially sensitive to these properties may play the critical role in mediating the effects.

Considerable evidence exists that sensory systems, including tactual, visual, and auditory, utilize different neuronal elements to process transient and steadystate stimulus properties (e.g., Békésy, 1967; Gersuni, 1971; Sherman, Wilson, Kaas, \& Webb, 1976). With respect to the auditory system, Gersuni has suggested that the two types of neuron are organized into two functional systems for transmitting information about these different attributes of sound. Neurons of both types, described as "short-time constant" and "long-time constant" neurons, were identified at all levels of the auditory system from cochlear nucleus through auditory cortex; the short-time neurons were relatively more abundant at higher than at lower levels and the short-time mechanism was shown to transmit from periphery to cortex with great rapidity.

Efforts to identify specific areas of the brain, critical for lead stimulation modification of startle, have not been successful. Extensive destruction of rat frontal cortex (Hammond, 1974), septum, amygdala, or hippocampus (Kemble \& Ison, 1971), and bilateral lesions in nucleus reticularis pontis oralis, pontis caudalis, or gigantocellularis (Hammond, 1973) had no effect on lead-stimulus produced inhibition. More encouraging results were obtained when general nervous system activity was altered by means of barbiturate anesthesia (Hammond \& Ison, 1973). Because many subjects (rats) lost the inhibitory effect during the period of hyperreflexia but regained it during the period of increased drug uptake preceding areflexia, a simple blocking action by the drug appeared improbable. The investigators suggested that a more likely explanation would involve drug effects, acting at different rates, on both inhibitory and excitatory systems and thus disrupting the balance between them.

While little progress has been made in identifying critical central structures, Young, Cegavske, and Thompson (1976) have established that lead stimulation does not have its effect solely in sensory or internuncial pathways. By stimulating directly the final motor path for nictitating membrane extension in rabbits (abducens nucleus), they were able to show both inhibitory and excitatory effects dependent on the lead interval and duration of prior tone onsets and offsets. Inhibitory effects were briefer than those reported here, in agreement with Ison and Leonard's (1971) conclusion that facilitatory lead effects are relatively stronger in rabbit than in rat. Gernandt and Ades (1964) had earlier described relatively low-level effects of acoustic prestimulation on spinal ventral root response in strychninized cats. During strychnine hyperexcitability, unilateral click stimulation produced equal bilateral, ventral-root responses which inhibited, for lead times up to $70 \mathrm{msec}$, the monosynaptic and polysynaptic local segmental reflex elicited by shock stimulation of dorsal root. One of the most interesting findings was that the effect occurred only with transient click stimuli. Continuous white noise failed to evoke any motoneuron activity.

These auditory-induced, spinal motor effects were not abolished by decerebration or cerebellectomy (Gernandt \& Ades, 1964). However, the pathway between ear and ventral root was not direct. Latencies of $17-21 \mathrm{msec}$, recorded for the motor responses evoked by single-click stimulation, were much longer than the approximately $8 \mathrm{msec}$ delay estimated for a direct connection. They implicate, therefore, a pathway through the synaptic relays of the lower brainstem reticular formation, perhaps via inferior colliculus, a finding which is not incompatible with the barbiturate effects obtained by Hammond and Ison (1973).

Although the gap between neurophysiological and behavioral data is wide, the neurophysiological findings reviewed appear capable of accounting for the behavioral data within the constraints imposed: that is, the need to account for discordant effects on response latency and magnitude, the association of facilitatory effects with "long" time stimulation, and the association of inhibitory effects with a transient stimulus change. A possible mechanism would involve activation of both short- and longtime neurons by lead stimulation, with the short-time system acting through an indirect path to produce delayed inhibition of motoneurons and the long-time system acting to facilitate or prime portions of the startle pathway. An effective startle stimulus, occurring shortly afterwards, could thus initiate a startle response more rapidly through the primed path, but augmentation of the response through unprimed paths would be damped by the later-arriving inhibition.

While the indirect path of the proposed short-time effect remains obscure, it would not be surprising if, in agreement with the work of Gernandt and Ades (1964), the inhibitory effect could be mediated at low levels of the nervous system. The very robustness and lack of variability of a phenomenon 
found in diverse species argues for a primitive mechanism. This is not to suggest that the effect is unimportant for high-level functions. Gersuni (1971) proposed that one function of the short-time system was rapid conduction to higher centers of the information that an environmental change had been detected, while the more slowly acting long-time system allowed for finer analysis of stimulus information. Such a division is consonant with evidence from information-processing research that stimulus detection and recognition (analysis) are different processes (e.g., Massaro, 1972). Further, the process of recognizing even simple sounds can be disrupted by subsequent stimulation for a period up to approximately $250 \mathrm{msec}$ (Massaro, 1970). It would be advantageous, therefore, if a mechanism existed for dampening strong motor reflexes to a second stimulus that occurred during the period of analysis. It may not be fortuitous that the change-detecting, leadstimulus inhibitory effect provides such a mechanism.

\section{REFERENCE NOTE}

1. Hall, R. J., \& Cusack, B. L. The measurement of eye behavior: Critical and selected reviews of voluntary eye movement and blinking. U.S. Army Technical Memorandum 18-72, Human Engineering Laboratory, 1972.

\section{REFERENCES}

BÉkÉsy, G. Von. Sensory inhibition. Princeton, N.J: Princeton University Press, 1967.

BERG, K. M. Elicitation of acoustic startle in the human. Unpublished $\mathrm{PhD}$ thesis, University of Wisconsin, 1973.

BLOCH, R. M. Inhibition and facilitation effects of a prepulse on the human blink response to a startle pulse. Unpublished $\mathrm{PhD}$ thesis, University of Wisconsin, 1972.

DAllos, P. The auditory periphery: Biophysics and physiology. New York: Academic Press, 1973.

DunNetr, C. W. A multiple comparison procedure for comparing several treatments with a control. Journal of the American Statistical Association, 1955, 50, 1096-1121.

Gernandt, B. E., \& Ades, H. W. Spinal motor responses to acoustic stimulation. Experimental Neurology, 1964, 10, 52-66.

GERSUNI, G. V. Temporal organization of the auditory function. In G. V. Gersuni (Ed.), Sensory processes at the neuronal and behavioral levels. New York: Academic Press, 1971. Pp. 85-114.

GRAHAM, F. K. The more or less startling effects of weak prestimulation. Psychophysiology, 1975, 12, 238-248.

Graham, F. K., Putnam, L. E., \& Leavitt, L. A. Lead-stimulation effects on human cardiac orienting and blink reflexes. Journal of Experimental Psychology: Human Perception and Performance, 1975, 1, 161-169.

GreEnhouse, S. W., \& GeIsSER, S. On methods in the analysis of profile data. Psychometrika, 1959, 24, 95-112.

Hammond, G. R. Lesions of pontine and medullary reticular formation and prestimulus inhibition of the acoustic startle reaction in rats. Physiology and Behavior, 1973, 8, 535-537.

Hammond, G. R. Frontal cortical lesions and prestimulus inhibition of the rat's acoustic startle reaction. Physiological Psychology, 1974, 2, 151-156.

Hammond, G. R., \& Ison, J. R. Stimulus-produced reflex inhibition in the rat during induction of and recovery from barbiturate anesthesia. Journal of Comparative and Physiological Psychology, 1973, 84, 436-444.
Hammond, G. R., McAdam, D. W., \& Ison, J. R. Effects of prestimulation on the electromyographic response associated with the acoustic startle reaction in rats. Physiology and Behavior, 1972, 8, 535-537.

Hoffman, H. S., Marsh, R. R., \& Stein, N. Persistence of background acoustic stimulation in controlling startle. Journal of Comparative and Physiological Psychology, 1969, 68, 280-283.

Hoffman, H. S., \& Wible, B. L. Temporal parameters in startle facilitation by steady background signals. Journal of the Acoustical Society of America, 1969, 45, 7-12.

Hoffman, H. S., \& Wible, B. L. Role of weak signals in acoustic startle. Journal of the Acoustical Society of America, 1970, 47, 489-497.

Ison, J. R., \& HAMmond, G. R. Modification of the startle reflex in the rat by changes in the auditory and visual environments. Journal of Comparative and Physiological Psychology, 1971, 75, 435-452.

Ison, J. R., \& LEONARD, D. W. Effects of auditory stimuli on the amplitude of the nictitating membrane reflex of the rabbit (Oryctolagus coniculus). Journal of Comparative and Physiological Psychology, 1971, 75, 157-164.

Ison, J. R., McAdam, D. W., \& Hammond, G. R. Latency and amplitude changes in the acoustic startle reflex of the rat produced by variation in auditory prestimulation. Physiology and Behavior, 1973, 10, 1035-1039.

Kemble, E. D., \& Ison, J. R. Limbic lesions and the inhibition of startle reactions in the rat by conditions of preliminary stimulation. Physiology and Behavior, 1971, 7, 925-928.

KraUter, E. E., Leonard, D. W., \& Ison, J. R. Inhibition of human eye blink by brief acoustic stimulus. Journal of Comparative and Physiological Psychology, 1973, 84, 246-251.

Landis, C., \& HunT, W. A. The startle pattern. New York: Farrar \& Rinehart, 1939.

LICKLIDER, J. C. R. Basic correlates of the auditory stimulus. In S. S. Stevens (Ed.), Handbook of experimental psychology. New York: Wiley, 1951. Pp. 985-1039.

MAssaro, D. W. Preperceptual auditory images. Journal of Experimental Psychology, 1970, 85, 411-417.

Massaro, D. W. Preperceptual images, processing time, and perceptual units in auditory perception. Psychological Review, 1972, 79, 124-145.

McEwen, W. K. Secretion of tears and blinking. In H. Davson (Ed.), The eye (Vol. 3). New York: Academic Press, 1962. Chapter 10.

Putnam, L. E. Mechanisms of startle modification by background acoustic stimulation. Unpublished $\mathrm{PhD}$ thesis, University of Wisconsin, 1975.

Sherman, S. M., Wilson, J. R., KaAs, J. H., \& Webb, S. V. Xand $\mathrm{Y}$-cells in the dorsal lateral geniculate nucleus of the owl monkey (Aotus trivirgatus). Science, 1976, 192, 475-477.

STITT, C. L. Modification of the pigeon's visual startle reaction by the sensory environment. Unpublished $\mathrm{PhD}$ thesis, Bryn Mawr College, 1975.

Stitt, C. L., Hoffman, H. S., Marsh, R., \& Boskoff, K. J. Modification of the rat's startle reaction by an antecedent change in the acoustic environment. Journal of Comparative and Physiological Psychology, 1974, 86, 826-836.

Young, R. A., Cegavske, C. F., \& Thompson, R. F. Toneinduced changes in excitability of abducens motoneurons and of the reflex path of nictitating membrane response in rabbit (Oryctolagus cuniculus). Journal of Comparative and Physiological Psychology, 1976, 90, 424-434.

\section{NOTE}

1. An analysis of the log magnitude scores of these 18 subjects yielded the same significant factors obtained in the 27 -subject total sample.

(Received for publication August 11, 1976; revision accepted December 3, 1976.) 